\title{
Fatty Acid Methyl Ester from Waste Edible Oil: Combustion Characteristics
}

\author{
Nguyen Ngoc Dung*
}

Ho Chi Minh City University of Food Industry

DOI: $10.36347 /$ sjet.2020.v08i07.001

| Received: 26.06.2020 | Accepted: 07.07.2020 | Published: 16.07.2020

*Corresponding author: Nguyen Ngoc Dung

Abstract

Original Research Article

Fatty acid methyl ester (FAME) is the most attractive alternative fuel for diesel engines which could resolve ongoing concerns about environmental issues and sustainable energy due to its carbon-neutral characteristic. The main objective of this research was to generate fundamental data on ignition delay and combustion characteristics of FAME. Experiments were carried out in a constant-volume combustion vessel under diesel-engine conditions to study the effects of temperature and pressure on ignition delay and combustion characteristics. Several kinds of BDF fuels (biodiesel fuel or FAME) produced from waste edible oil and having different properties were tested and compared to a standard gas-oil. The experimental results show the strong influence of temperature and pressure on the ignition and combustion processes for the tested fuels. It is shown that (i) the fresh BDF exhibits a longer ignition delay than the gas-oil (conventional diesel fuel), (ii) a small amount of isopropyl alcohol as an additive in BDF promotes the ignition, (iii) the oxidized BDF with acid value changed from 0.1 for the fresh one to $0.22(\mathrm{KOHmg} / \mathrm{g})$ has a shortened ignition delay, to almost the same as standard gas-oil, and (iv) the blend of BDF with twenty percent by volume to gas-oil results in a reasonable ignition delay. Additionally, the results at pressure $2 \mathrm{MPa}$, which simulates conditions of PCCI (premixed charge compression ignition) engine operations in future engine trends, present two-stage ignition and lowtemperature combustion characteristics for both BDF and gas-oil. These findings help improve considerations for the optimal design and operation of diesel engines fuelled with FAME.

Keywords: Ignition Delay, Diesel-Engine Combustion Characteristics, Biodiesel Fuel, Constant-Volume Vessel.

Copyright @ 2020: This is an open-access article distributed under the terms of the Creative Commons Attribution license which permits unrestricted use, distribution, and reproduction in any medium for non-commercial use (NonCommercial, or CC-BY-NC) provided the original author and source are credited.

\section{INTRODUCTION}

For decades, petroleum has been the main energy source for internal combustion engines and has played an important role in contributing to world economic development. This fuel source has widespread popularity based on its advantages of high energy density, ease to use, and low cost compared to alternative fuels. However, petroleum products have caused serious problems to the environment such as global warming and air pollution. Recently, the increased consumption of fossil fuels has led to the near-exhaustion of these natural resources. Many alternative fuels have been applied to decrease the usage of petroleum, and intensive efforts have been made to reduce the total emissions from diesel engines. Utilizing biomass resources may be the most promising solution, which particularly benefits the environment and protects resources as well. Fatty acid methyl ester (FAME) or biodiesel fuel (BDF) is recognized as the most promising candidate among alternative fuels.
Many researchers have concentrated on biodiesel fuels for their advantages such as its renewability; its biodegradability; and carbon neutrality [1]. Biodiesel fuels are produced from many renewable sources such as soybean oil [2], rapeseed oil [3], palm oil $[4,5]$, jatropha curcas oil [6,7], waste cooking oil $[8,9]$, and animal fat $[10,11]$. Direct use of such vegetable oils and its blends in diesel engines was reported to have many problems due to high viscosity and high phosphorous content $[12,13]$. To overcome these problems, the chemical reaction termed transesterification was applied to modify vegetable oils into vegetable oil esters. They are suitable for diesel engines and defined as FAME or BDF fuel.

Researchers have applied BDF and its blend directly to diesel engines without any modification [1420]. In general the combustion products of BDF were reported with lower emissions of regulated-gases such as carbon monoxide (CO), hydrocarbon (HC), particulate matter (PM), and smoke in comparison with 
standard diesel fuel, while the engine performances were reported unchanged $[6,14]$ or slightly lower $[20-$ 22]. However, many works have also concerned the increasing of nitrogen oxide $\left(\mathrm{NO}_{\mathrm{x}}\right)$ emission by applying BDF [10,23]. Some researchers indicated that $\mathrm{NO}_{\mathrm{x}}$ emission was greatly affected by engine characteristics (engine design) and fuel properties [24]. In general, the $\mathrm{NO}_{\mathrm{x}}$ emissions results for biodiesel fuels derived from soybean or rapeseed oils with low cetane number, often gives higher $\mathrm{NO}_{\mathrm{x}}$ emissions, while the results for fuels from other sources like palm or jatropha curcas oil are similar compared to conventional diesel fuel [6]. The researchers have pointed out that the solution overcoming the problems of $\mathrm{NO}_{\mathrm{x}}$ is by controlling advance injection time [3,24]. However, the researchers in the field of combustion did not have a sufficient amount of fundamental data on the strong effect of fuel properties on ignition and combustion characteristics.

In Kyoto city, waste edible oils from general households, restaurants and cafeterias have been collected and used to produce biodiesel since 1997 [8]. This activity has many benefits such as recycling waste edible oil, reducing automobile emissions, reducing carbon dioxide emissions, improving people awareness of environmental issues and vitalizing local communities. Biodiesel fuel produced from this waste edible oil is currently used for most garbage trucks and some of municipal buses. The application of this fuel was reported to contribute to a reduction in carbon dioxide $\left(\mathrm{CO}_{2}\right)$ of about 4,000 tons per year. Our previous paper investigated the influences of BDF from waste edible oils for short-term and long-term application on commercial vehicles with different engine systems, in which the solutions for trouble and improvement measures have been examined [8]. However, the information of functional parameters correlated to the control of ignition and combustion processes was required for future engine systems.

The main objective of this research was to provide the fundamental data of ignition delay and combustion characteristics of various BDF fuels and to compare them against those of standard gas-oil (conventional diesel fuel). Experiments were conducted in a constant-volume combustion vessel under dieselengine conditions to study the effects of temperature and pressure on the ignition delay and combustion characteristics. High-speed shadowgraph photography was applied to analyze spray penetration, flame development and combustion phenomena. Based on the obtained data, the ignition and combustion characteristics of these fuels were discussed with emphasis on the mixture formation and heat release rate.

\section{EXPERIMENTAL SETUP \\ Constant-Volume Combustion Vessel}

In this research, the experiments for ignition delay and combustion characteristics of BDFs were carried out in a constant-volume combustion vessel. The special vessel was applied to generate and simulate a high temperature and high-pressure environment like diesel-engine combustion occurring near top dead center (TDC). The vessel in this research was made similar to the vessel in previous papers $[25,26]$.

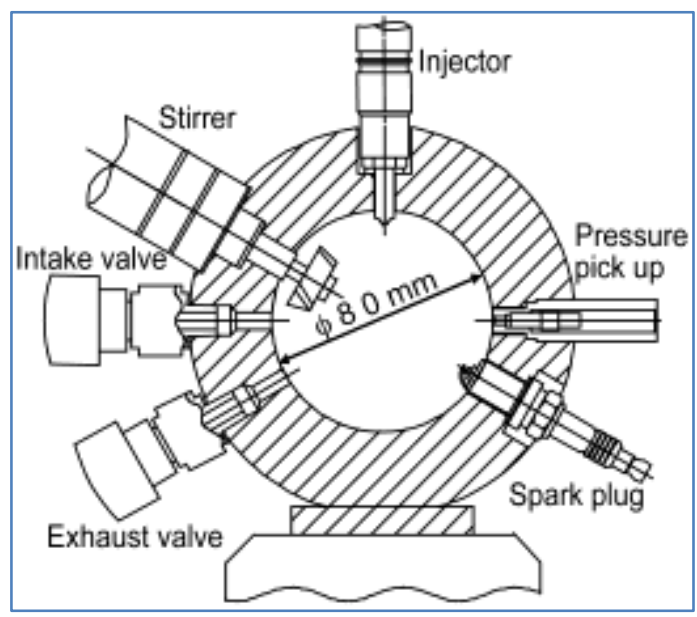

Fig-1: Cross section of constant-volume vessel

Figure 1 shows a schematic of the crosssection of the combustion vessel for this study. The chamber is $80 \mathrm{~mm}$ in diameter, $30 \mathrm{~mm}$ in depth with a volume of approximately $150 \mathrm{~cm}^{3}$ and fitted with quartz windows on both sides for optical accessing. The six important parts needed to simulate diesel combustion are also indicated in this figure. These include an intake valve for induction of a premixed gas into the combustion chamber; an exhaust valve for removing burned-gas; a spark plug for igniting the premixed charge; a mixing fan (stirrer) used to maintain a spatially uniform temperature in the chamber before the fuel injection; a single-shot injector and a pressure transducer. Fuel was supplied by common-rail system and injected to the chamber by single-shot injector mounted at the top of the chamber. The pressure of the combustion chamber was measured by piezoelectric, absolute pressure transducer (Kistler 6052A). The pressure obtained was used to calculate ignition delay and heat-release rate [26]. Fuel spray penetration and flame development were visualized and recorded by high-speed shadowgraph using digital camera Phantom v.7. To reduce vapor condensation on the combustion windows and to get high quality shadowgraph images, these windows were heated up to $230^{\circ} \mathrm{C}$ before each experiment. In this research, camera was controlled to record at a speed of $10,000 \mathrm{fps}$ and exposure time 30 $\mu \mathrm{s}$. 


\section{Experimental Procedure}

The two step combustion discussed previously by Siebers DL and Naber et al. [27,28] is used to simulate diesel TDC combustion processes in the constant-volume combustion vessel. To start the experiment, premixed gas $\left(\mathrm{C}_{2} \mathrm{H}_{4}, \mathrm{H}_{2}, \mathrm{O}_{2}\right.$ and $\left.\mathrm{N}_{2}\right)$ prepared in a mixing tank is introduced into the combustion chamber through the intake valve, and ignited by spark plug. The initial pressure of premixed combustible gas is selected to obtain the requirement of temperature $\left(T_{i}\right)$, pressure $\left(p_{i}\right)$, oxygen mole-fraction $\left(r_{\mathrm{O} 2}\right)$ similar to diesel-combustion near TDC. The vessel temperature is determined as a thermodynamically averaged temperature by a knowing initial temperature, initial pressure and composition of the premixed gas before ignition [26,28]. After the premixed charge combustion, the pressure decays because of the heat transfer to the walls. When the desired temperature and pressure are obtained, a signal is sent to common-rail system to actuate the injector. After a delay period, injected fuel autoignites and burns in an appropriate environment. To eliminate large temperature variations in the combustion chamber and to ensure homogeneous conditions before injection, a mixing fan is run 20 seconds before the ignition of the premixed combustible gas.

The experiments were conducted with five kinds of BDFs and standard gas-oil. For all experiments, fuel was injected at a fixed injection pressure of $80 \mathrm{MPa}$ by using a single-hole nozzle with diameter $\left(d_{N}\right)$ of $0.22 \mathrm{~mm}$. The fuel quantity controlled by adjusting the injection duration time was selected to obtain an equivalence ratio $(\square)$ of 0.22 at $T_{i}=800 \mathrm{~K}$ and $p_{i}=4 \mathrm{MPa}$ for every tested fuel, and the injection duration was fixed irrespective of temperature and pressure. As a base condition, the oxygen concentration or mole-fraction of oxygen $\left(r_{O_{2}}\right)$ in the vessel was set to $21 \%$, the pressure $\left(p_{i}\right)$ was fixed $4 \mathrm{MPa}$ and the temperature $\left(T_{i}\right)$ was varied in the range $600-1200 \mathrm{~K}$. At the later part of experiment, the pressure was reduced to $2 \mathrm{MPa}$ for the fresh BDF (BDF1) and gas-oil to investigate the effect of pressure on the ignition and combustion characteristics. Furthermore, shadowgraph images were taken at $T_{i}=700 \mathrm{~K}, p_{i}=4 \mathrm{MPa}$ to investigate spray penetration, flame development and mixture formation for BDFs and gas-oil.

\section{Fuels}

Five kinds of biodiesel fuels were tested in this research. They include (1) BDF1, the fresh BDF from waste cooking oil without additive; (2) BDF2, the fresh BDF with 3 percent IPA (isopropyl alcohol) as an additive for improving fluidity at low-temperature and aclube $146^{\mathrm{R}}$ (Sanyo Chemical Industries, Ltd.) as an anti-oxidation additive; (3) BDF3, the aged and oxidized BDF with acid value $[\mathrm{mgKOH} / \mathrm{g}]$ of 0.22 compared to 0.1 for the fresh one; (4) Blend BDF, with blend by volume of 20 percent BDF1 and 80 percent gas-oil; (5) Blend BDF3, with blend by volume of 20 percent BDF3 and 80 percent gas-oil. These BDF fuels were produced from waste cooking oil via the wellrefined transesterification process [8].

Table-1: Properties of tested fuels

\begin{tabular}{|l|l|c|c|c|c|c|c|}
\hline \multicolumn{2}{|l|}{ Fuel } & BDF1 & BDF2 & BDF3 & BlendBDF1 & BlendBDF3 & Gas-oil \\
\hline Density $\left(15^{0} \mathrm{C}\right)$ & $\mathrm{g} / \mathrm{cm}^{3}$ & 0.8851 & 0.882 & 0.8865 & 0.8434 & 0.844 & 0.825 \\
\hline Viscosity $\left(30^{0} \mathrm{C}\right)$ & $\mathrm{mm}^{2} / \mathrm{s}$ & 4.532 & 4.416 & 4.756 & 3.437 & 3.478 & 3.281 \\
\hline Flash point & $\left({ }^{0} \mathrm{C}\right)$ & 180.5 & 30.5 & 150.5 & 91.5 & 86.5 & 67 \\
\hline Cetane Number & & 52.3 & - & - & - & - & $55-60$ \\
\hline Distillation $\left({ }^{0} \mathrm{C}\right)$ & 0 & 312 & 88 & 89 & 210 & 205 & 165 \\
\hline & 5 & 332 & 94 & 330 & 235 & 234 & 185 \\
\hline & 10 & 336 & 329 & 335.5 & 249 & 249 & 205 \\
\hline & 50 & 340 & 339 & 340 & 296.5 & 296 & 280 \\
\hline & 90 & 345 & 349 & 344 & 340 & 340 & 330 \\
\hline & 98 & 348 & 352 & 345 & 353 & 352 & 350 \\
\hline Acid number & $\mathrm{KOHmg} / \mathrm{g}$ & 0.1 & 0.12 & 0.22 & - & - & - \\
\hline Oxidation stability & $\mathrm{hr}$ & 6.1 & 6.3 & 1.2 & - & - & - \\
\hline Peroxide number & $\mathrm{meq} / \mathrm{kg}$ & 3 & 3 & 75 & - & - & - \\
\hline
\end{tabular}




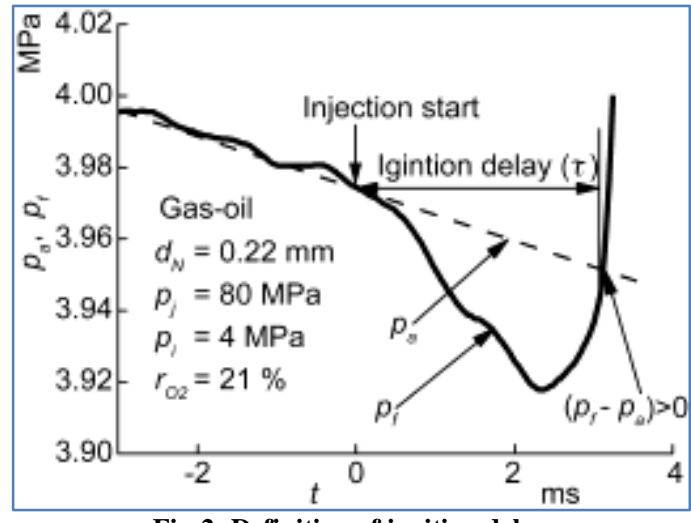

Fig-2: Definition of ignition delay

Table 1 shows the typical properties of tested fuels. In general, biodiesel fuels have higher density, higher viscosity, higher flash point and lower cetane number than gas-oil. With a small amount of IPA additive in BDF2, the flash point and distillation temperature at 5 percent changes drastically in comparison with the fresh BDF1 without additive. In comparison with other biodiesel fuels, physical and chemical properties of the oxidized BDF3 are altered by time resulting in increased viscosity, acid number, peroxide number and decreased oxidation stability. The change of fuel properties may greatly affect the fuel ignition delay and combustion characteristics.

\section{Ignition Delay Definition}

Ignition delay or the process of autoignition is the most important fundamental parameter in the control of the combustion processes in direct-injection diesel engines. Generally, ignition delay is defined as the time (or crank angle) between the start of injection and the start of heat release. In this research, pressure recovery delay was applied to define ignition delay $(\tau)$ for tested liquid fuels and described detail in Fig. 2 with the results for standard gas-oil. Ignition delay or pressure-recovery delay was defined as the time from start of injection until the pressure in the vessel rises to just above $p_{a},\left(p_{f}-p_{a}>0\right)$. In this figure, the dashed line $p_{a}$ displays pressure history generated by burning combustible premixed gas, and the solid line $p_{f}$ indicates the actual chamber pressure with fuel injection. During this time, fuel is continuously injected and vaporized, at the same time both physical and chemical processes take place. The physical process involves atomization, vaporization and fuel-air mixing phenomena, while the chemical process is related to temperature, pressure, fuel properties and oxygen concentration.

\section{RESULTS AND DISCUSSIONS}

Results and discussion are mainly divided into three parts. In the first part, we discuss spray penetration and development for BDF1, BDF2, BDF3 and gas-oil based on the visualization data. In the second, we concentrate on the discussion of spontaneous ignition and combustion characteristics for different neat and blend BDFs with the variation of temperature. Moreover, in the final part, we focus on the effects of pressure on ignition and combustion characteristics.

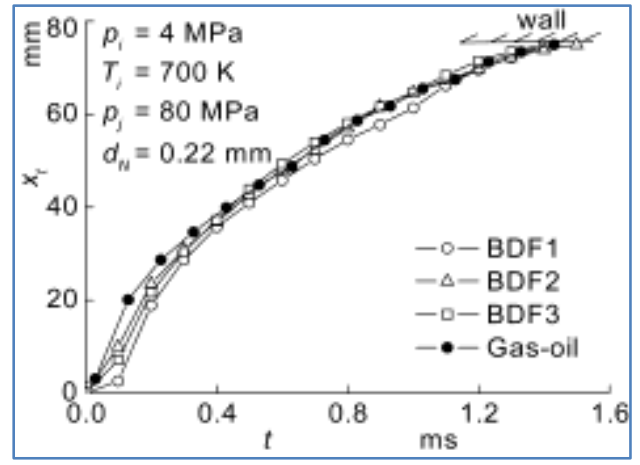

Fig-3: Spray-penetration lengths of BDF1, BDF2, BDF3, and gasoil. Chamber temperature and pressure are $700 \mathrm{~K}$ and $4 \mathrm{MPa}$, respectively

\section{Penetration and Development of Fuel Sprays}

Prior to the main discussion on ignition delay and combustion characteristics of biodiesel fuels, spray penetration and flame development of fresh BDF with and without additive (BDF1 and BDF2), of the oxidized BDF3 and of gas-oil are discussed. Shadowgraph images were used to analyze spray penetration length, mixture formation, and flame development for these fuels. The experiments were conducted at $T_{i}=700 \mathrm{~K}, p_{i}$ $=4 \mathrm{MPa}, p_{j}=80 \mathrm{MPa}, d_{N}=0.22 \mathrm{~mm}$ and $r_{O 2}=21 \%$.

Figure 3 presents the penetration length of reacting liquid fuel sprays. The graph displays the penetration length for various BDF fuels and gas-oil sprays, $x_{t}$, versus the time from injection start $(t)$. In this figure, high viscosity and high density of BDF fuels can be visually observed by slightly shorter $x_{t}$ values than gas-oil. In more detail, all of the tested BDFs indicate shorter $x_{t}$ than gas-oil as $t<0.4 \mathrm{~ms}$. Thereafter, the penetration length of BDF2 and BDF3 sprays are almost the same as those for gas-oil and they reach the vessel wall at an identical time. For BDF1, exhibited spray penetration length is shorter due to poor atomization and slow evaporation. The difference of $x_{t}$ among BDFs suggests that the chemical compositions of BDF2 and BDF3, altered by the additive and the oxidation reaction, also affected the atomization process.

Shadowgraph photos in Fig. 4 shows spray penetration and flame development to provide more explanations about the effects of fuel properties on mixture formation and combustion process for the tested fuel. The differences of spray penetration, spray configuration and flaming region were recorded and illustrated on the shadowgraph images. In Fig. 4, every row corresponds to an individual fuel, and demonstrates the spray penetration and development from the start until the end of injection time with an image time interval of $0.5 \mathrm{~ms}$. 


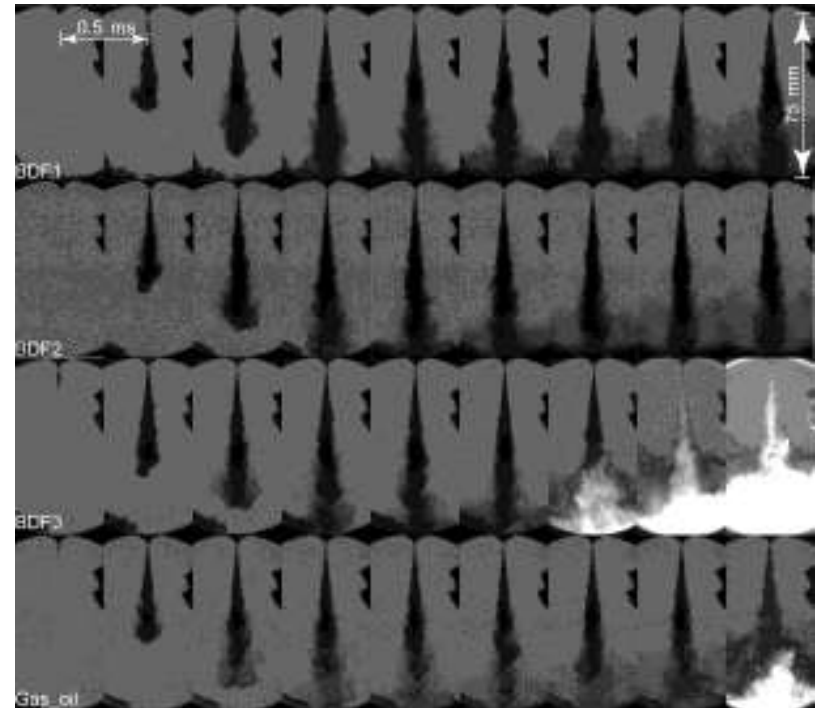

Fig-4: Shadowgraph images of spray penetration and development of BDF1, BDF2, BDF3, and gas-oil at the base condition. Chamber temperature and pressure are $700 \mathrm{~K}$ and $4 \mathrm{MPa}$, respectively

The observation result shows a slightly different profile of shade density and flame luminosity for different BDFs and gas-oil photos at every column. At $t=0.5 \mathrm{~ms}$ (the second column photos from left), BDF2 and BDF3 sprays exhibit similar shade profiles while the results of BDF1 and gas-oil sprays show a slight difference. At this time, the image of gas-oil spray shows a small amount of evaporation at the shear layer. At $t=1 \mathrm{~ms}$, the differences of mixing and evaporation processes for the tested fuels can be easily separated by different spray-density superimposed on shadowgraph images. The high density and high viscosity of BDF1 and BDF2 sprays show slow evaporation with a very dark spray-core. The narrow range of higher distillation temperatures in biodiesel fuels may also retard the evaporation at lower temperature. For BDF3 and gas-oil, the injected fuels are observed to be evaporated and mixed with surrounding air at the area around $50 \mathrm{~mm}$ from the nozzle exit, where the bulk of hot air is entrained into the spray core through a shear layer. At $t=1.5 \mathrm{~ms}$, all fuel-spays have developed and reached to the vessel wall. At this time, the different evaporation and mixing processes can be easily distinguished for different liquid sprays. For BDF1 and BDF 2, the mixing area is just around the spray tip attaching to the vessel. For gas-oil and BDF3, the evaporation and well-mixing of fuels penetrates over the downstream of sprays. Therefore, mixture formation of BDF3 and gas-oil may occur earlier than that of BDF1 and BDF2. The well-mixing process and accumulated fuel during ignition delay may cause rapid heat-release in correlation with luminous flames at the time near injection end of $t=3.2 \mathrm{~ms}$.

Effects of Temperature on Ignition Delay and Combustion Characteristics for Various BDFs and Gas-oil at 4 MPa

In diesel-combustion conditions, previous researches with other fuel-sprays have found the great effect of temperature on ignition delay. This dependence is associated with mixture formation and chemical kinetics processes during autoignition. In this part, we discuss the effects of temperature $\left(T_{i}\right)$ on the ignition delay $(\tau)$ and combustion characteristic for various BDF fuels and compare to that of gas-oil at the base condition.

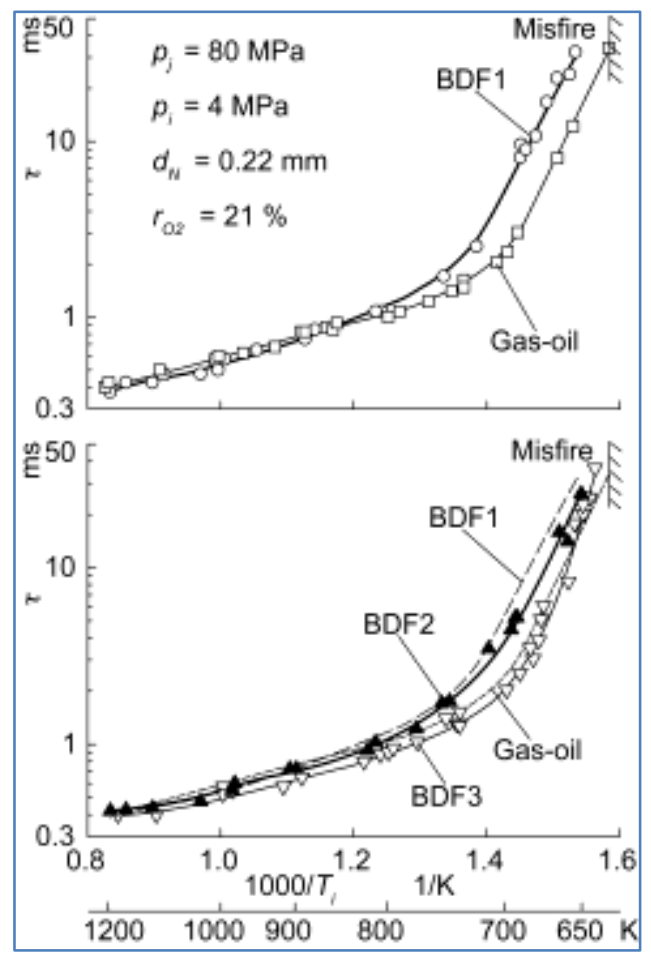

Fig-5: Effects of $T_{i}$ on $\tau$ for pure BDF1, BDF2, BDF3, and gas-oil. Chamber pressure at injection time is $4 \mathrm{MPa}$. Graphs are shown separately for clarity.

Figure 5 shows the effect of $T_{i}$ on $\tau$ for different biodiesel fuels of BDF1, BDF2, BDF3 and gas-oil at $p_{i}=4 \mathrm{MPa}$. The result is drawn as an Arrhenius form to present the importance of chemical kinetics. The tested BDFs and gas-oil exhibit similar ignition delay trends: As temperature decreases, 
ignition delay slightly increases at higher $T_{i}$ but largely increases at lower $T_{i}$. In comparison with gas-oil, BDF1 (fresh BDF) exhibits almost the same values of $\tau$ at $T_{i}$ higher than $850 \mathrm{~K}$, whereas a longer $\tau$ at lower $T_{i}$ showing the lower cetane number of the biodiesel fuel. Among BDF fuels, BDF1 with its high density and viscosity displays the longest ignition delay with especially slow evaporation and mixing process as in the previous discussion for these fuels. In addition, it is noted that both fuels hold the same slope in Arrhenius curve at lower $T_{i}$, representing almost the same identical activation energy of chemical reaction. A small amount of IPA and aclube146 in BDF2 may promote ignition to make $\tau$ shorter than BDF1, but still much longer than gas-oil at $T_{i}<850 \mathrm{~K}$. The difference in $\tau$ between BDF1 and BDF2, however, is only slight despite a very low flash point of BDF2. In contrast, the oxidized biodiesel,
BDF3, produced from the same process and the same source as other BDFs in this research, exhibits much shorter ignition delay and even shorter than gas-oil in the whole range of $T_{i}$. The oxidized BDF3 has very high peroxide number, which is 25 times higher than that for fresh biodiesel fuels. Hydro-peroxides in BDF3 may easily tend to decompose to free radicals, which initiate ignition and promote combustion. In addition, such peculiar kinetics of BDF3 possibly results in a higher slope of Arrhenius curve or larger activation energy at lower $T_{i}$, which may affect the combustion processes. In previous discussion of spray penetration and flame development, BDF3 showed faster evaporation and mixing processes than BDF1 and BDF2, which may also elevate ignitability.

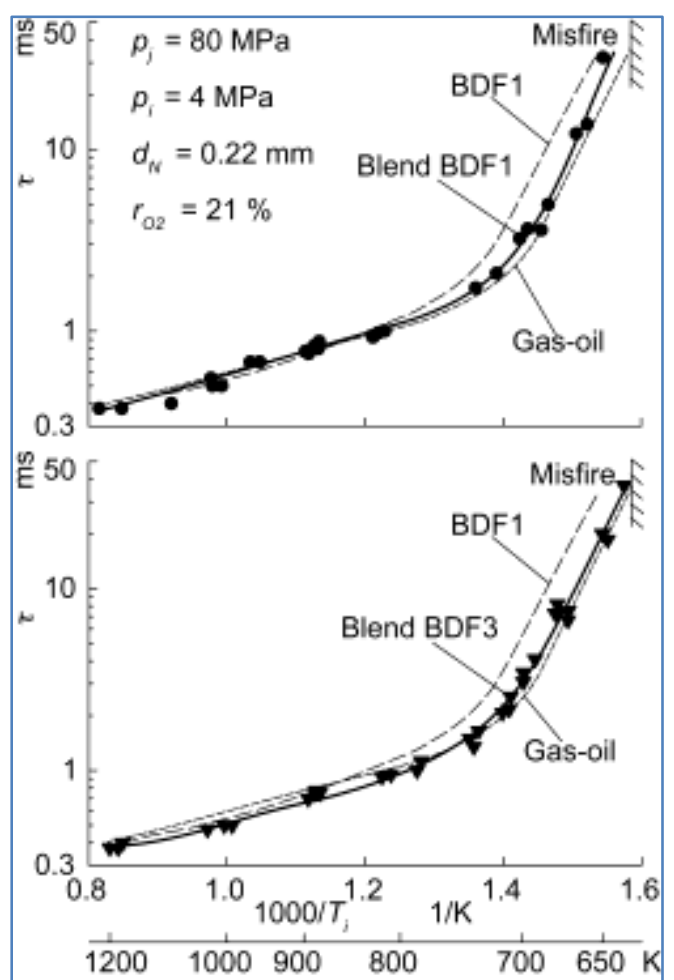

Fig-6: Effects of $T_{i}$ on $\tau$ for blend BDF1, blend BDF3, and gas-oil. Chamber pressure at injection time is 4 MPa. Graphs are shown separately for clarity

Figure 6 shows ignition delays for other tested fuels, the blend BDF1 and the blend BDF3. Ignition delay trend for these blend BDFs is quite similar to the neat ones. In this figure, the 20 percent BDF1 blended to gas-oil slightly prolongs ignition delay compared to the standard gas-oil at $T_{i}<800 \mathrm{~K}$. At higher temperature, however, the ignition delay trend of blend BDF1 seems to be same as that of gas-oil. For the result of blend BDF3, the ignition delay is quite similar to gas-oil's, but it is slightly shorter at $T_{i}$ higher than 800 $\mathrm{K}$ and longer at $T_{i}$ lower than $700 \mathrm{~K}$.

The results in Fig.5 and Fig. 6 show that a reasonably short ignition delay of $1-2 \mathrm{~ms}$ for engine application can be obtained at $T_{i}$ around $700-800 \mathrm{~K}$ for BDFs and gas-oil. This temperature seems a little lower than TDC temperatures in direct-injection compression ignition engines [29]. In this temperature range, the effects of fuel properties on ignition delay can be easily distinguished. For the other observation, the long ignition delay of BDFs (except BDF3) at temperatures under $800 \mathrm{~K}$ suggests that engines will be more difficult to ignite at cold-start conditions and may possibly give higher a misfire limit when they run with biodiesel fuel. However, under warm-up engine conditions or higher temperature [29], BDFs exhibit slightly shorter ignition delay than gas-oil. 

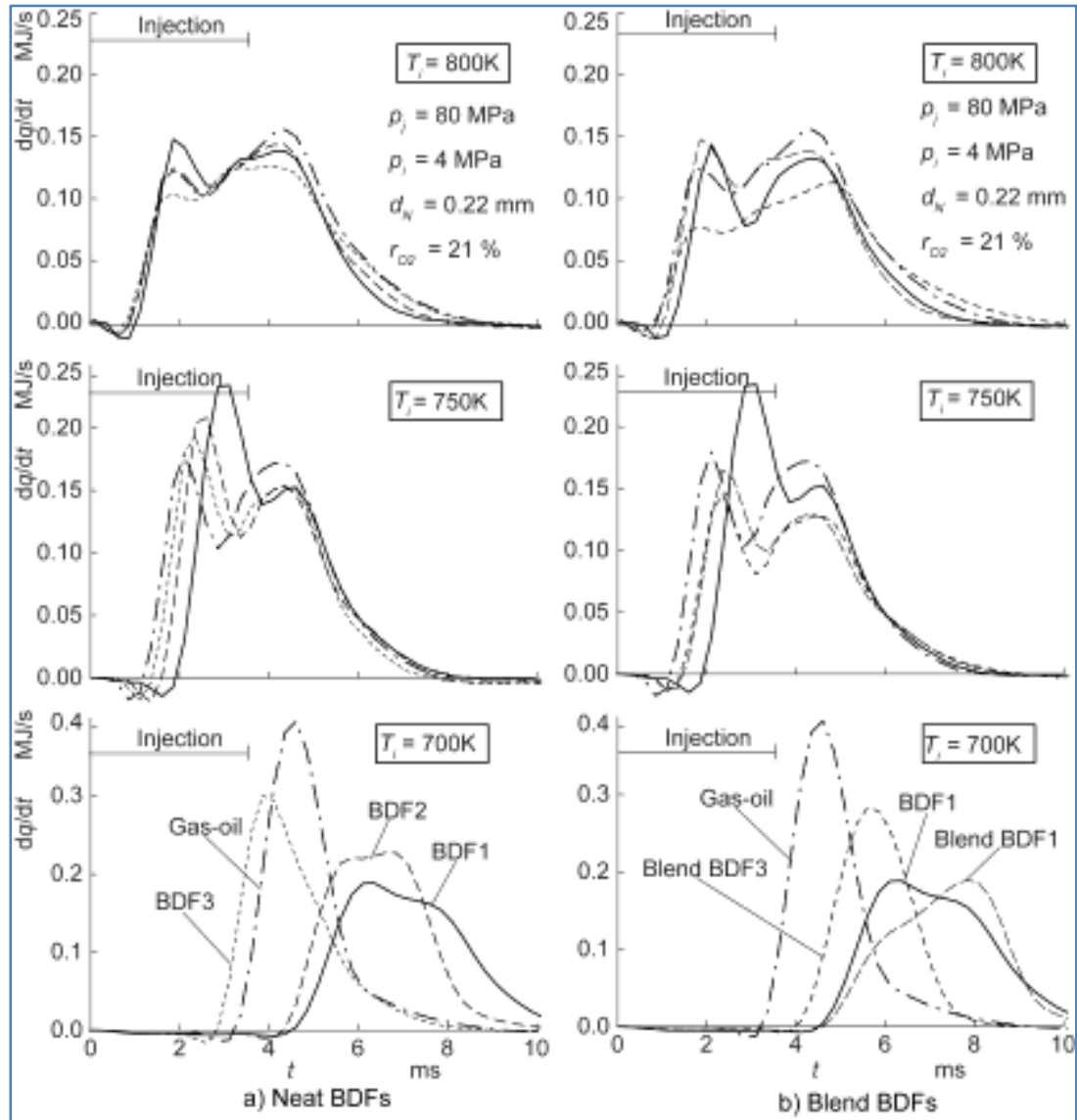

Fig-7: Effects of $T_{i}$ on $\mathrm{d} q / \mathrm{d} t$ for various BDF fuels and gas-oil. Chamber pressure at injection time is $4 \mathrm{MPa}$. Graphs are shown separately for clarity

Figure 7 shows the combustion histories, represented by the change of heat-release rate $\mathrm{d} q / \mathrm{d} t$ for different BDFs and gas-oil at $T_{i}=700 \mathrm{~K}, 750 \mathrm{~K}$ and $800 \mathrm{~K}$. The change of $\square$ with the variation of $T_{i}$ in those fuels greatly influences the combustion processes. The heat-release rates shown in this figure demonstrate the combustion of tested fuels, with a typical ignition delay for diesel engine application with premixed and diffusive combustion, and a longer ignition delay with only premixed combustion.

At $T_{i}=800 \mathrm{~K}$, the typical progress of $\mathrm{d} q / \mathrm{d} t$ is demonstrated for all fuels. The premixed combustion occurs after ignition delay $\square$ of around $1 \mathrm{~ms}$, and its peak increases with $\square$. After a certain period of premixed combustion, the diffusive combustion is followed by a peak at the injection end. Particularly in BDF3, a shorter ignition delay suppresses the premixed combustion to make the period of diffusive combustion longer. Although similar trends of typical progress of $\mathrm{d} q / \mathrm{d} t$ are observed at $T_{i}=750 \mathrm{~K}$, only BDF1 has a much longer ignition delay of around $2 \mathrm{~ms}$ exhibits a larger degree of premixed combustion. At $T_{i}=700 \mathrm{~K}$, however, the injected fuels are well mixed with air during the longer ignition delay, and then show only premixed combustion. In addition, except for neat BDF3 and gas-oil, ignition delay becomes longer than the injection period, at $4 \mathrm{~ms}$, resulting in a very slow combustion.
Effects of Temperature on Ignition Delay and Combustion Characteristics for BDF1 and Gas-Oil at $2 \mathrm{MPa}$

Pressure $\left(p_{i}\right)$ is the other parameter that strongly affects the ignition in diesel engines. In this section, we focus on studying effects of pressure $\left(p_{i}\right)$ on ignition delay and combustion characteristics for BDF1 and gas-oil. Experiments were conducted at a low pressure of $2 \mathrm{MPa}$ with temperature variation from 600 to $1200 \mathrm{~K}$. In addition, this condition was conducted with the purpose to simulate premixed-charge compression ignition (PCCI) conditions for future diesel engine trends.

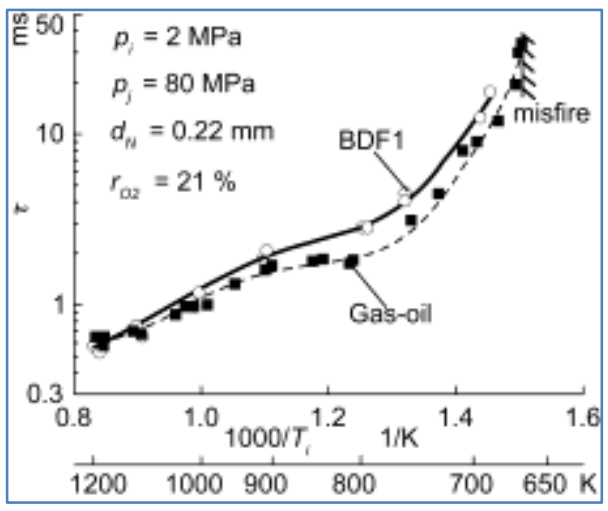

Fig-8: Effects of $T_{i}$ on $\tau$ for BDF1 and gas-oil. Chamber pressure at the injection time is $2 \mathrm{MPa}$. 
Figure 8 shows ignition delay for BDF1 and gas-oil at $p_{i}=2 \mathrm{MPa}$. Both fuels exhibit similar ignition delay trends: As pressure decreases to $2 \mathrm{MPa}$, ignition delay greatly increases. In addition, ignition delay curves of BDF1 and gas-oil in Fig. 8 are observed to have significant differences in comparison with their respective results at $p_{i}=4 \mathrm{MPa}$ (in Fig. 5). In addition, the result in Fig. 8 shows a 'bend' in ignition delay curves for both BDF1 and gas-oil, which reflects the effects of cool flame or negative temperature coefficient (NTC) regime on ignition and combustion for the tested fuels.

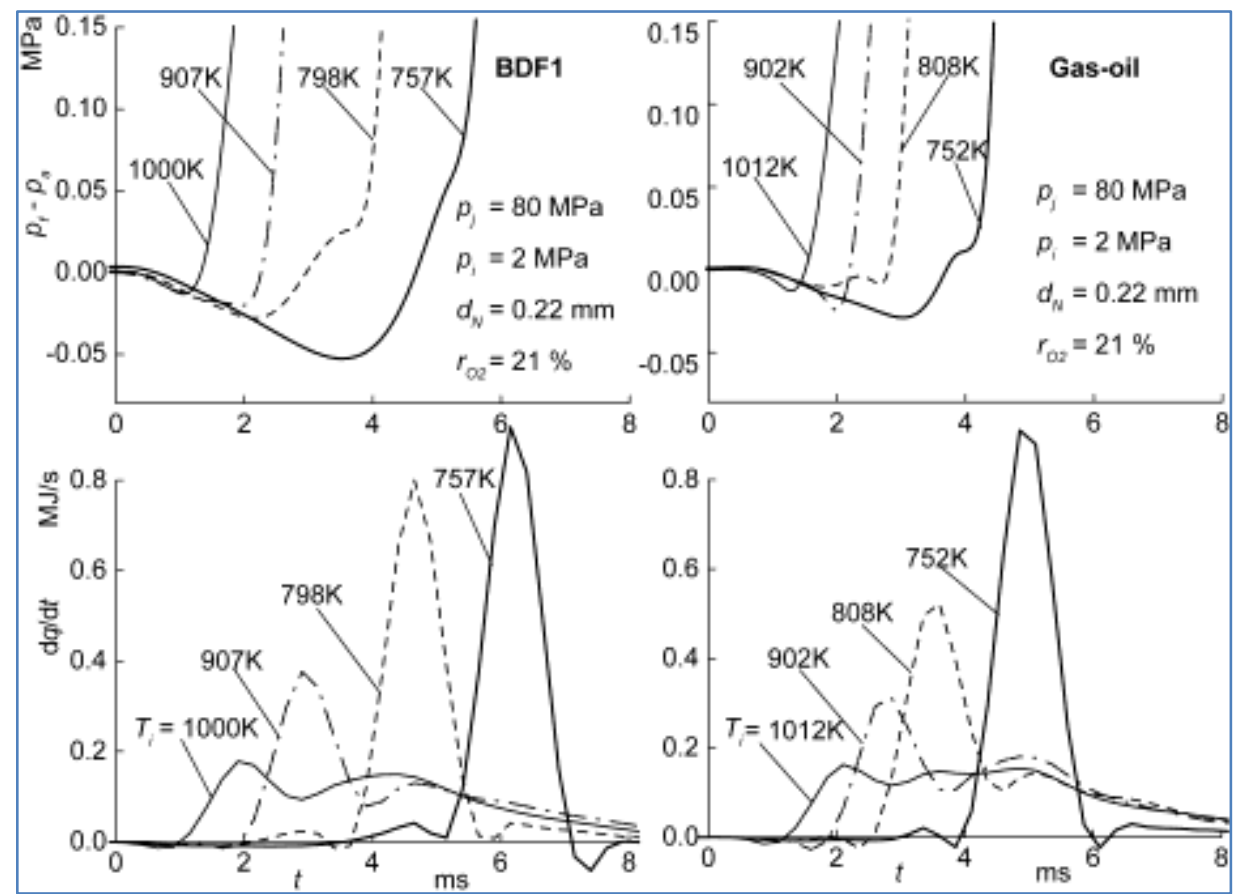

Fig-9: Effects of $T_{i}$ on pressure rise and $\mathrm{d} q / \mathrm{d} t$ for BDF1 and gas-oil. Chamber pressure and fuel injection pressure are $2 \mathrm{MPa}$ and $80 \mathrm{MPa}$, respectively

The "bend" in the ignition delay curves in Fig. 8 is caused by a change in ignition characteristics. Figure 9 shows pressure histories and rates of heatrelease starting from the time of injection for several temperatures around the "bend" in ignition delay curves of BDF1 and gas-oil. The pressure histories for these two fuels have exhibited two-stage ignition for temperature around and lower than $900 \mathrm{~K}$, but not for the highest temperature of around $1000 \mathrm{~K}$ does not. The first-stage ignition appears as a small pressure rise after the initial pressure drop from fuel evaporation. The second or main stage ignition follows a short time later with a large pressure rise. In other words, five to twenty percent of the total heat-release rate occurs during an initial delay period. This initial release is followed by a slowing of reactions over a second delay period, the end of which is marked by sudden release of the remaining heat. Furthermore, the results in Fig. 9 also show that the diffusive combustion occurs for temperature higher than the 'bend' temperature in ignition delay curves. At temperatures from 750 to 900 $\mathrm{K}$ for 'bend' temperature, combustions are observed with rapid heat-release increase during premixed combustion and followed by minor diffusive combustion. For the lower temperatures, BDF1 and gasoil exhibit with only premixed stage combustion.

\section{CONCLUSION}

The ignition delay and combustion characteristics of neat and blend FAME fuels were fundamentally studied in this research under directinjection compression-ignition conditions. All experiments were carried out in a constant-volume combustion vessel with variable temperature and pressure. From the obtained results, we conclude as follows:

Temperature and pressure greatly affect the ignition delay and combustion characteristics of the tested fuels. Ignition delay increases as temperature and pressure decrease.

- The fresh biodiesel fuels with and without additive exhibit longer ignition delay than gas-oil. In addition, the high viscosity and high density of BDFs have been observed in the results to slow evaporation and slow mixing process.

- A small amount of isopropyl alcohol and aclube146 serves to promote ignition capability. These additives may possibly help BDF easily evaporate and mix with the hot air in the combustion chamber at the low temperature conditions. In addition, hydro-peroxides in oxidized BDF3 promote ignition and combustion. From this point of view, the BDF fuels produced from different sources will 
have different ignition and combustion characteristics.

- The blends of 20 percent BDF fuels by volume in gas-oil do not much affect to ignition delay and combustion characteristics in comparison with the standard gas-oil. This suggests that a blend percentage of less than 20 percent of BDF fuel can be used in direct-injection diesel engine without problems in controlling combustion system.

- The ignition and combustion for both BDF and gas-oil at pressure $2 \mathrm{MPa}$ are different compared to the diesel condition of $4 \mathrm{MPa}$, which features twostage ignition with low-temperature combustion.

\section{ACKNOWLEDGMENTS}

The authors would like to thank to Power and Combustion Lab at Graduate School of Energy Science, Kyoto University for supporting experiment. Thanks to Mr. Akihito Fujita for his valuable time in experiment work.

\section{REFERENCES}

1. Ali, Y., \& Hanna, M. A. (1994). Alternative diesel fuels from vegetable oils. Bioresource technology, 50(2), 153-163.

2. Liu, X., He, H., Wang, Y., Zhu, S., \& Piao, X. (2008). Transesterification of soybean oil to biodiesel using $\mathrm{CaO}$ as a solid base catalyst. Fuel, 87(2), 216-221.

3. Nwafor, O. M. I., Rice, G., \& Ogbonna, A. I. (2000). Effect of advanced injection timing on the performance of rapeseed oil in diesel engines. Renewable energy, 21(3-4), 433-444.

4. Yusof, M. Z., Aziz, A. A., \& Mukti, M. A. (1987). Performance of palm oil methyl esters as alternative fuel for diesel engines. In International Pacific Conference on Automotive Engineering, 4th, 1987, Melbourne, Australia.

5. Hashimoto, N., Ozawa, Y., Mori, N., Yuri, I., \& Hisamatsu, T. (2008). Fundamental combustion characteristics of palm methyl ester (PME) as alternative fuel for gas turbines. Fuel, 87(15-16), 3373-3378.

6. Reksowardojo, I. K., Lubis, I. H., Manggala, W., Brodjonegoro, T. P., Soerawidjaja, T. H., Arismunandar, W., ... \& Ogawa, H. (2007). Performance and exhaust gas emissions of using biodiesel fuel from physic nut (Jatropha Curcas L.) oil on a direct injection diesel engine (DI) (No. 2007-01-2025). SAE Technical Paper.

7. Tapanes, N. C. O., Aranda, D. A. G., de Mesquita Carneiro, J. W., \& Antunes, O. A. C. (2008). Transesterification of Jatropha curcas oil glycerides: theoretical and experimental studies of biodiesel reaction. Fuel, 87(10-11), 2286-2295.

8. Nakamura, K., Shioji, M., Ikegami, M., Hanada, Y., Matsushita, M. (2006). Influence of the biodiesel "tempura oil" in diesel vehicles. Proceedings of the 2nd joint international conference on "Sustainable Energy and Environment (SEE 2006)", Thailand; Nov 21-23

9. Meng, X., Chen, G., \& Wang, Y. (2008). Biodiesel production from waste cooking oil via alkali catalyst and its engine test. Fuel processing technology, 89(9), 851-857.

10. Graboski, M. S., \& McCormick, R. L. (1998). Combustion of fat and vegetable oil derived fuels in diesel engines. Progress in energy and combustion science, 24(2), 125-164.

11. Bhatti, H. N., Hanif, M. A., \& Qasim, M. (2008). Biodiesel production from waste tallow. Fuel, 87(13-14), 2961-2966.

12. Reksowardojo, I. K., Brodjonegoro, T. P., Arismunandar, W., Sopheak, R., \& Ogawa, H. (2007). The Combustion and Exhaust Gas Emission of a Direct Injection Compression Ignition Engine Using Physic Nut Oil (Jatropha Curcas L. oil) (No. 2007-01-3622). SAE Technical Paper.

13. Lance, D. L., \& Andersson, J. D. (2004). Emissions performance of pure vegetable oil in two European light duty vehicles. SAE transactions, 904-923.

14. Scholl, K. W., \& Sorenson, S. C. (1993). Combustion of soybean oil methyl ester in a direct injection diesel engine. SAE Transactions, 14501462.

15. Han, M., Cho, K., Sluder, C. S., \& Wagner, R. M. (2008). Soybean and coconut biodiesel fuel effects on combustion characteristics in a light-duty diesel engine (No. 2008-01-2501). SAE Technical Paper.

16. Zheng, M., Mulenga, M. C., Reader, G. T., Wang, M., Ting, D. S., \& Tjong, J. (2008). Biodiesel engine performance and emissions in low temperature combustion. Fuel, 87(6), 714-722.

17. Staat, F., \& Gateau, P. (1995). The effects of rapeseed oil methyl ester on diesel engine performance, exhaust emissions and Long-Term behavior-A summary of three years of experimentation. SAE transactions, 1-7.

18. Sundaresan, M., Chandrasekaran, S., \& Porai, P. T. (2007). Analysis of combustion, performance and emission characteristics of blends of methyl esters of jatropha oil (MEJ) in DI diesel engine (No. 2007-32-0066). SAE Technical Paper.

19. Wu, Y. P. G., Lin, Y. F., \& Chang, C. T. (2007). Combustion characteristics of fatty acid methyl esters derived from recycled cooking oil. Fuel, 86(17-18), 2810-2816.

20. Banapurmath, N. R., Tewari, P. G., \& Hosmath, R. S. (2008). Performance and emission characteristics of a DI compression ignition engine operated on Honge, Jatropha and sesame oil methyl esters. Renewable energy, 33(9), 1982-1988.

21. Hribernik, A., \& Kegl, B. (2007). Influence of biodiesel fuel on the combustion and emission formation in a direct injection (DI) diesel engine. Energy \& fuels, 21(3), 1760-1767.

22. Zhang, X., Wang, H., Li, L., Wu, Z., Hu, Z., \& Zhao, H. (2008). Characteristics of Output Performances and Emissions of Diesel Engine 
Employed Common Rail Fueled with Biodiesel Blends from Wasted Cooking Oil (No. 2008-011833). SAE Technical Paper.

23. Ali, Y., Hanna, M. A., \& Leviticus, L. I. (1995). Emissions and power characteristics of diesel engines on methyl soyate and diesel fuel blends. Bioresource Technology, 52(2), 185-195.

24. Agarwal, D., Sinha, S., \& Agarwal, A. K. (2006). Experimental investigation of control of $\mathrm{NOx}$ emissions in biodiesel-fueled compression ignition engine. Renewable energy, 31(14), 2356-2369.

25. Kitamura, Y., Kee, S. S., Mohammadi, A., Ishiyama, T., \& Shioji, M. (2006). Study on NOx Control in Direct-Injection PCCI CombustionFundamental Investigation Using a ConstantVolume Vessel. SAE Transactions, 358-367.
26. Ishiyama, T., Shioji, M., Ihara, T., Inoue, T., \& TAKADA, N. (2003). Characteristics of spontaneous ignition and combustion in unsteady high-speed gaseous fuel jets. SAE transactions, 1787-1797.

27. Siebers, D. L. (1985). Ignition delay characteristics of alternative diesel fuels: implications on cetane number. SAE transactions, 673-686.

28. Naber, J. D., Siebers, D. L., Westbrook, C. K., Caton, J. A., \& Di Julio, S. S. (1994). Natural gas autoignition under diesel conditions: experiments and chemical kinetic modeling. SAE transactions, 1735-1753.

29. Heywood, J. B. (1988). Combustion engine fundamentals. $1^{a}$ Edição. Estados Unidos. 